\title{
Kajian Kelayakan Fisik Pantai Seribu Ranting Jepara Sebagai Kawasan Wisata Pantai
}

\author{
Dyah Pitaloka Novitasari*, Ibnu Pratikto, Chrisna Adhi Suryono \\ Departemen IImu Kelautan, Fakultas Perikanan dan IImu Kelautan, Universitas Diponegoro \\ Jl. Prof.H.Soedarto S.H, Tembalang,Semarang, Jawa Tengah 50275 Indonesia \\ ${ }^{*}$ Corresponding author, e-mail : pipitaloka10@gmail.com
}

\begin{abstract}
ABSTRAK : Pantai Seribu Ranting terletak di Desa Panggung, Kecamatan Kedung, Kabupaten Jepara, Jawa Tengah. Pantai Seribu Ranting memiliki potensi alam yang dapat dikembangkan untuk kegiatan pariwisata. Tujuan penelitian ini untuk mengevaluasi kelayakan fisik Pantai Seribu Ranting sebagai kawasan wisata pantai di Kabupaten Jepara dengan mengkaji parameter fisik pantai dan analisis SWOT. Penelitian ini bermanfaat mengetahui kelayakan kawasan wisata Pantai Seribu Ranting sebagai kawasan wisata pantai. Penelitian dilakukan pada bulan Desember 2018 dengan metode purposive sampling. Hasil penelitian menunjukkan bahwa Pantai Seribu Ranting sesuai untuk kegiatan wisata pantai karena hasil pengukuran di stasiun 1, stasiun 2, dan stasiun 3 menunjukkan nilai IKW diatas $80 \%$. Nilai IKW yang diperoleh tergolong dalam tingkat kesesuaian $\mathrm{S} 1$, walaupun terdapat beberapa parameter yang kurang mendukung seperti perairan yang terlalu keruh. Akan tetapi hal itu dapat disiasati dengan menonjolkan kelebihannya seperti pasir putih, pantai yang landai, dan tidak adanya biota berbahaya. Analisis SWOT di Pantai Seribu Ranting menghasilkan tiga prioritas utama, yaitu: Memanfaatkan kondisi alam yang ada untuk menambah daya tarik wisata, membuat atraksi eduwisata tambak garam, dan membuat arena olahraga pantai.
\end{abstract}

Kata Kunci : eduwisata; pantai seribu ranting; Jepara

\section{Physical Feasibility Study of Jepara Seribu Ranting Beach as a Beach Tourism Area}

ABSTRACT : Seribu Ranting Beach is located in Panggung Village, Kedung Subdistrict, Jepara, Central Java. Seribu Ranting Beach have natural potential that can be developed for ecotourism. The purpose of this research is to evaluate the physical advisability of Seribu Ranting Beach as a beach tourism area in Jepara by studying the physical parameters of the beach and SWOT analysis. The advantage of this research is to know the advisability of ecotourism in Seribu Ranting Beach as beach tourism. The research has been carried out in December 2018 with a purposive sampling method. The results showed that Seribu Ranting Beach is suitable for beach tourism activities because the measurement results at station 1, 2, and 3 showed that IKW values are above $80 \%$. The IKW values that have been obtained are classified as a level of S1 suitability, although there are some parameters that are less supportive like turbid water and a lot of garbage. However, this can be dealt by highlighting its advantages such as white sand, sloping beaches, and the absence of dangerous biota. The SWOT analysis on Seribu Ranting Beach produced three main priorities, namely: utilizing existing natural conditions to increase tourist attraction, making edutourism attractions of salt ponds, and creating a beach sports arena.

Keywords: Edupark; Seribu Ranting Beach; Jepara

\section{PENDAHULUAN}

Pantai Seribu Ranting merupakan kawasan pantai berpasir putih di pesisir Kabupaten Jepara. Pantai Seribu Ranting terletak di Desa Panggung, kecamatan Kedung, Kabupaten Jepara. Pantai Seribu Ranting memiliki potensi yang dapat dikembangkan menjadi daerah wisata pantai. Wisata pantai merupakan wisata yang objek dan daya tariknya bersumber dari potensi bentang laut maupun bentang darat pantai. Pengembangan potensi pariwisata pantai yang ada di Kabupaten 
Jepara, perlu diadakan kajian untuk mengetahui kelayakan Pantai Seribu Ranting sebagai objek wisata. Pantai Seribu Ranting merupakan pantai dengan keunikan terletak di tepi tambak garam. Berbagai aktivitas wisata rekreasi pantai yang dilakukan antara lain seperti bersantai, naik perahu, fotografi, menikmati panorama laut, olahraga pantai, dan rekreasi keluarga.

Ekowisata merupakan kegiatan pariwisata dengan objek wisata berupa kenampakan alam. Ekowisata merupakan kegiatan mengunjungi kawasan alamiah yang relatif tidak terganggu dengan tujuan melihat, mempelajari, dan mengagumi wajah keindahan alam, flora, fauna dan aspek budaya baik di masa lampau maupun sekarang yang terdapat di kawasan tersebut (Puspita, 2015). Pengembangan kawasan wisata pantai merupakan kegiatan yang memiliki aktivitas berkaitan dengan kelautan, baik diatas permukaan laut maupun kegiatan yang dilakukan di bawah pemukaan laut. Wisata pantai merupakan wisata yang objek dan daya tariknya bersumber dari potensi bentang laut maupun bentang darat pantai. Suatu obyek wisata akan semakin ramai dikunjungi oleh wisatawan apabila mempunyai suatu atraksi wisata sebagai daya tarik wisata (Fendeli, 2000).

Kajian kelayakan wisata merupakan suatu kajian untuk menilai kecocokan dari suatu aktivitas yang dilakukan disuatu kawasan dengan mempertimbangkan berbagai parameter. Kajian kelayakan fisik Pantai Seribu Ranting sebagai kawasan wisata pantai akan memberikan gambaran apakah objek wisata tersebut dapat dikatakan sesuai atau tidak sebagai objek wisata pantai (Prihantanto, 2014). Penelitian ini bertujuan untuk mengevaluasi kelayakan Pantai Seribu Ranting Jepara sebagai kawasan wisata pantai di Kabupaten Jepara. Manfaat dari penelitian ini yaitu diketahuinya kelayakan kawasan wisata Pantai Seribu Ranting sebagai kawasan wisata pantai dan diharapkan memberikan masukan kepada pihak - pihak terkait dalam pengembangan Pantai Seribu Ranting sebagai kawasan wisata pantai.

\section{MATERI DAN METODE}

Penelitian ini menggunakan analisis data primer dan data sekunder. Pengumpulan data primer dilakukan melalui observasi langsung di lokasi penelitian yang terdiri dari data lebar pantai, kemiringan pantai, tipe pantai, ketersediaan air tawar, ukuran butir pasir, kedalaman perairan, kecerahan perairan, dan penutupan lahan pantai. Data sekunder diperoleh melalui studi pustaka milik pemerintah, dimana terdiri dari Badan Meteorologi Klimatologi dan Geofisika Maritim Semarang, Jawa Tengah, Dinas Pariwisata Kabupaten Jepara, dan Pemerintah Desa Panggung Kabupaten Jepara. Data yang dikumpulkan meliputi: kondisi geologi, oseanografi, klimatologi, serta batas administratif.

Penelitian ini dilakukan dengan menggunakan metode deskriptif yaitu metode yang bermaksud untuk membuat pencandraan atau penggambaran mengenai situasi, kondisi atau kejadian pada daerah yang menjadi objek kajian penelitian. Data primer diperoleh secara langsung dengan metode purposive sampling yang merupakan pengambilan data dengan pertimbangan tertentu. Lokasi penelitian dapat dilihat pada Gambar 1.

\section{Pengukuran Parameter Lingkungan}

Parameter lingkungan yang diukur berdasarkan modifikasi Yulianda (2007), adalah parameter fisika yang meliputi kedalaman, kecerahan, dan ketersediaan air tawar, dan parameter topografi pantai yang meliputi tipe pantai, ukuran butir pasir, lebar pantai, kemiringan pantai, dan biota berbahaya.

Pengukuran kedalaman dilakukan dengan menggunakan tongkat berskala. Nilai yang ditunjukkan pada tongkat ini merupakan nilai kedalaman stasiun penelitian. Secara fisik kedalaman pantai dikategorikan cukup baik yaitu apabila perairan pantai dangkal $\leq 5$ meter sebagai objek wisata berenang (Dewi, 2017).

Kecerahan perairan diukur dengan menggunakan secchi disk yang diikat dengan tali kemudian diturunkan ke perairan secara perlahan hingga tidak tampak kemudian ukur panjang tali. Secara perlahan tarik secchi disk ke atas hingga warna putih terlihat kembali kemudian ukur panjang tali. Perairan yang dangkal menunjang adanya kegiatan wisata pantai. Kedalaman 0-5 meter merupakan kedalaman yang paling sesuai untuk kegiatan rekreasi pantai (Haris, 2003).

Ketersediaan air tawar diukur dengan cara mengukur jarak dari stasiun penelitian menuju sumber air tawar terdekat yang dapat dimanfaatkan oleh pengunjung. Pengukuran dilakukan 
dengan menggunakan roll meter. Jarak sumber air tawar paling sesuai untuk kegiatan pariwisata adalah kurang dari 0,5 km (Handayawati, 2010).
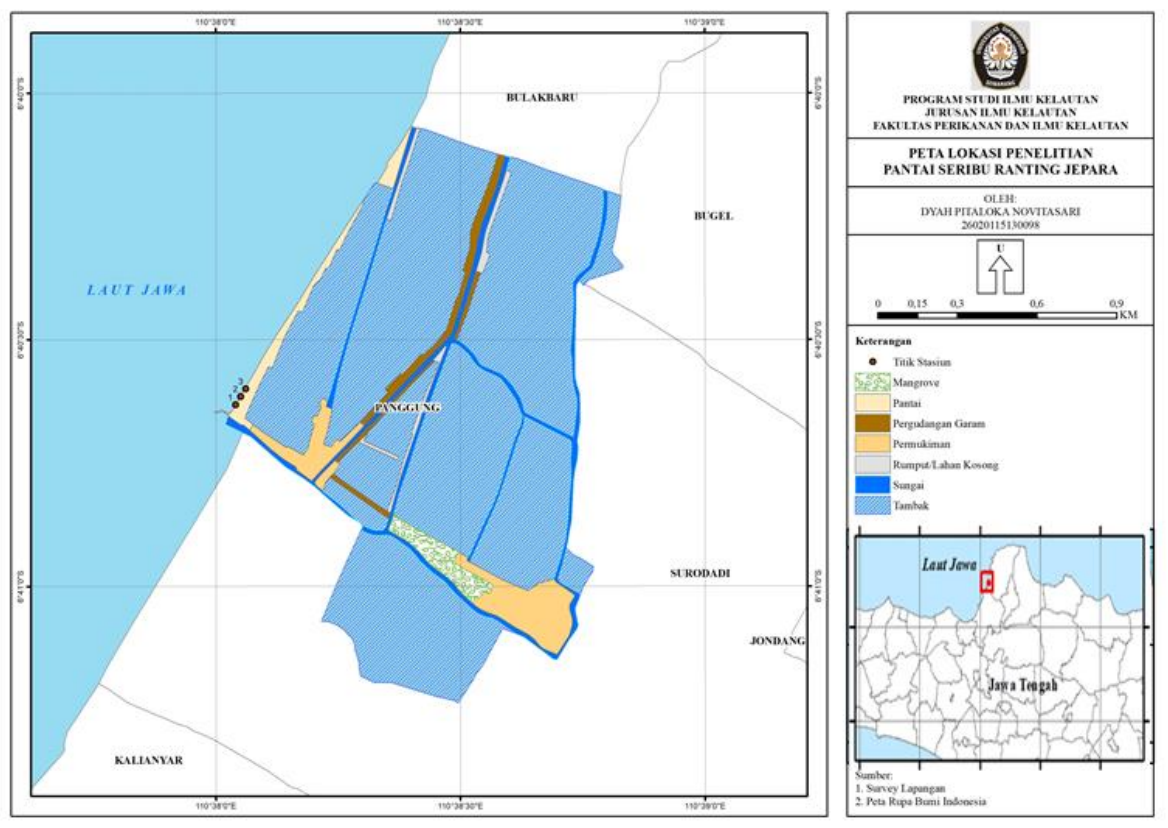

Gambar 1. Peta Lokasi Penelitian

Penentuan tipe pantai dan material dasar perairan dilakukan berdasarkan pengamatan visual dilapangan. Lebar pantai diketahui dengan mengukur jarak antara vegetasi terakhir di pantai dengan batas pasang tertinggi menggunakan roll meter.

Kemiringan pantai menurut Wunani (2014), diukur dengan cara menancapkan tiang berskala setinggi 2 meter pada batas pasang tertinggi dan vegetasi terakhir. Selang yang telah diisi air selanjutnya dibentangkan dan dilihat ketinggian air dari masing - masing tongkat. Kemudian diukur jarak dari kedua tongkat secara tegak lurus menggunakan roll meter.

Pasir dari masing - masing stasiun pengukuran diambil untuk dilakukan analisis ukuran butir pasir. Langkah - langkah yang dilakukan menurut Wunani (2014), yaitu :

a. Sampel dikeringkan di bawah sinar matahari. Kemudian dilakukan pengeringan kembali dalam oven dengan suhu $100^{\circ} \mathrm{C}$ selama 1 jam untuk menghilangkan kadar air secara sempurna.

b. Sampel diambil sebanyak 100 gram kemudian dimasukkan ke dalam shieve shaker dan diayak kurang lebih 10 menit.

c. Jumlah pasir pada setiap ukuran mesh ditimbang, kemudian data yang didapat ditabulasikan.

Pengamatan biota berbahaya dilakukan dengan melakukan snorkeling dan pengamatan visual disekitar stasiun penelitian dan wawancara kepada penduduk setempat. Menurut Yulianda (2007), biota yang tergolong berbahaya bagi pengunjung diantaranya: ubur - ubur, bulu babi, dan ular laut.

\section{Analisa Data}

Analisis kesesuaian wisata adalah analisis yang bertujuan untuk mengetahui kesesuaian wisata pada suatu kawasan dalam penggunaan lahan pada kawasan tersebut. Penentuan kesesuaian wisata pantai berdasarkan parameter-parameter yang mengandung kriteria-kriteria yang memiliki skor dan bobot dari tiap parameter, dimana pemberian bobot berdasarkan tingkat kepentingan suatu parameter terhadap perencanaan kawasan wisata. Bobot yang diberikan adalah 5 (lima), 3 (tiga), dan 1 (satu).

Setelah menentukan bobot dan skor, kemudian dilakukan perkalian skor dan bobot untuk mendapatkan nilai indeks pada tiap parameter. Penilaian kesesuaian wisata berdasarkan dari penjumlah nilai indeks dari parameter kemudian dimasukan kedalam rumus. Analisis kesesuaian 
yang digunakan yaitu analisis kesesuaian wisata berdasarkan Yulianda (2007) dengan rumus Indeks Kesesuaian Wisata sebagai berikut:

$$
\mathrm{IKW}=(\Sigma \mathrm{Ni} / \mathrm{Nmaks}) \times 100 \%
$$

Keterangan : IKW : Indeks Kesesuaian Wisata; Ni : Nilai Parameter ke-I (bobot x skor); Nmaks : Nilai maksimum suatu kategori wisata

Kelas kesesuaian lahan wisata rekreasi pantai dibagi menjadi 4 (empat) kelas kesesuaian yaitu: S1 (Sangat Sesuai) : 80-100\%; S2 (Cukup Sesuai) : 60-80\%; S3 (Sesuai Bersyarat) : 35$60 \%$; S4 (Tidak Sesuai) : $<35$

\section{Analisis SWOT}

Menurut Rangkuti (2005), analisis SWOT merupakan sarana perencanaan strategi, pengambilan keputusan serta kebijakan dengan memperhatikan situasi dan kondisi lingkungan internal dan eksternal. Analisis SWOT merumuskan strategi dengan cara memaksimalkan kekuatan dan peluang serta meminimalkan kelemahan dan ancaman. Variabel dalam analisis SWOT diberi rating mulai dari 1 (tidak penting) sampai dengan nilai 4 (sangat penting). Dilakukan pembobotan dengan nilai $0-1,0$. Nilai 0 berarti tidak penting. Nilai 1,0 berarti sangat penting. Bobot dan rating selanjutnya dikalikan untuk mendapatkan nilai skor.

\section{HASIL DAN PEMBAHASAN}

Perhitungan persentase nilai indeks kesesuaian wisata di Pantai Seribu Ranting Kabupaten Jepara dilakukan dengan mempertimbangkan semua parameter terkait. Hasil perhitungan persentase indeks kesesuaian wisata pada tiga stasiun pengamatan di Pantai Seribu Ranting menunjukkan angka diatas $80 \%$. Hasil ini menunjukkan bahwa Pantai Seribu Ranting layak sebagai wisata pantai karena termasuk kategori $\mathrm{S} 1$.

Tabel 1. Matriks Kesesuaian Wisata Pantai Kategori Rekreasi

\begin{tabular}{|c|c|c|c|c|c|c|c|c|c|c|}
\hline \multirow{2}{*}{ No } & \multirow{2}{*}{ Parameter } & \multirow{2}{*}{ Bobot } & \multicolumn{8}{|c|}{ Kategori dan Skor } \\
\hline & & & S1 & Skor & S2 & Skor & S3 & Skor & TS & Skor \\
\hline 1 & Kedalaman & 5 & $0-3 \mathrm{~m}$ & 3 & $3-6 m$ & 2 & $6-10 m$ & 1 & $>10 \mathrm{~m}$ & 0 \\
\hline 2 & Tipe Rantai & 5 & Rasir putih & 3 & $\begin{array}{l}\text { Dasir putib, } \\
\text { sedikit } \\
\text { berkarang }\end{array}$ & 2 & $\begin{array}{l}\text { Rasir hitam } \\
\text { berkarang, } \\
\text { sedikit } \\
\text { terial }\end{array}$ & 1 & $\begin{array}{c}\text { Lumpur } \\
\text { berbtau } \\
\text { terjal }\end{array}$ & 0 \\
\hline 3 & Lebar Rantai. & 5 & $>15 \mathrm{~m}$ & 3 & $10-15 m$ & 2 & $3-<10 \mathrm{~m}$ & 1 & $<3 \mathrm{~m}$ & 0 \\
\hline 4 & Kemiringan Pantai & 3 & $<10^{\circ}$ & 3 & $10-25^{\circ}$ & 2 & $25-45^{\circ}$ & 1 & $>45^{\circ}$ & 0 \\
\hline 5 & Material Dasac Rerairan. & 3 & Rasir. & 3 & $\begin{array}{l}\text { Karang } \\
\text { berpasir }\end{array}$ & 2 & $\begin{array}{c}\text { Pasir. } \\
\text { berlumbur }\end{array}$ & 1 & Lumpur & 0 \\
\hline 6 & Kecerahan Reraican & 1 & $75-100 \%$ & 3 & $50-75 \%$ & 2 & $25-50 \%$ & 1 & $<25 \%$ & 0 \\
\hline 7 & Ketersediaan Air Jawar & 1 & $<0,5 \mathrm{~km}$ & 3 & $0,5-1 \mathrm{~km}$ & 2 & $1-2 \mathrm{~km}$ & 1 & $>2 \mathrm{~km}$ & 0 \\
\hline 8 & Biota Berbahaya & 1 & Tidak ada & 3 & Bulu babi & 2 & $\begin{array}{l}\text { Bulu babi, } \\
\text { ubur-ubur }\end{array}$ & 1 & $\begin{array}{c}\text { ikan } \\
\text { pari, biu }\end{array}$ & 0 \\
\hline 9 & Renutupan Laban & 1 & $\begin{array}{c}\text { Kelapa. } \\
\text { lahaan } \\
\text { terbuka }\end{array}$ & 3 & $\begin{array}{l}\text { Belukar } \\
\text { rendah }\end{array}$ & 2 & $\begin{array}{l}\text { Belukar } \\
\text { tinggi }\end{array}$ & 1 & $\begin{array}{c}\text { Hutan } \\
\text { bakau, } \\
\text { pelabuh } \\
\text { an }\end{array}$ & 0 \\
\hline 10 & Ukuran Butir Pasir & 1 & $<0,25 \mathrm{~mm}$ & 3 & $\begin{array}{c}0,25-0,5 \\
\mathrm{~mm}\end{array}$ & 2 & $0,5-2 \mathrm{~mm}$ & 1 & $>2 \mathrm{~mm}$ & 0 \\
\hline
\end{tabular}


Tabel 2. Hasil Perhitungan Nilai IKW di Stasiun 1 Pantai Seribu Ranting

\begin{tabular}{|c|c|c|c|}
\hline Parameter & Bobot & Skor & $\mathrm{Ni}: \mathrm{BxS}$ \\
\hline Tipe Pantai & 5 & 3 & 15 \\
\hline Lebar Pantai & 5 & 2 & 10 \\
\hline Kemiringan Pantai & 5 & 3 & 15 \\
\hline Penutupan Lahan & 3 & 2 & 6 \\
\hline Ukuran Butir Pasir & 3 & 3 & 9 \\
\hline Ketersediaan Air Tawar & 3 & 3 & 9 \\
\hline Total $\left(\sum \mathrm{Ni}\right)$ & & & 64 \\
\hline
\end{tabular}

Tabel 3. Hasil Perhitungan Nilai IKW di Stasiun 2 Pantai Seribu Ranting

\begin{tabular}{llll}
\hline Parameter & Bobot & Skor & Ni:BxS \\
\hline Tipe Pantai & 5 & 3 & 15 \\
Lebar Pantai & 5 & 1 & 5 \\
Kemiringan Pantai & 5 & 3 & 15 \\
Penutupan Lahan & 3 & 2 & 6 \\
Ukuran Butir Pasir & 3 & 3 & 9 \\
Ketersediaan Air Tawar & 3 & 3 & 9 \\
\hline Total $\left(\sum \mathrm{Ni}\right)$ & & & 59 \\
\hline
\end{tabular}

Tabel 4. Hasil Perhitungan Nilai IKW di Stasiun 3 Pantai Seribu Ranting

\begin{tabular}{llll}
\hline Parameter & Bobot & Skor & Ni:BxS \\
\hline Tipe Pantai & 5 & 3 & 15 \\
Lebar Pantai & 5 & 2 & 10 \\
Kemiringan Pantai & 5 & 3 & 15 \\
Penutupan Lahan & 3 & 2 & 6 \\
Ukuran Butir Pasir & 3 & 3 & 9 \\
Ketersediaan Air Tawar & 3 & 2 & 6 \\
\hline Total $\left(\sum \mathrm{Ni}\right)$ & & & 61 \\
\hline
\end{tabular}

Total perhitungan nilai indeks kesesuaian wisata yang telah didapatkan dari setiap stasiun pengamatan selanjutnya dipersentasekan dengan dibagi oleh nilai total maksimal IKW, sehingga didapatkan kategori kesesuaian wisata (Tabel 5.)

Tabel 5. Kategori Tingkat Kesesuaian Wisata Pantai Seribu Ranting

\begin{tabular}{llll}
\hline Stasiun Pengamatan & Total & IKW & Kelas kesesuaian \\
\hline Stasiun 1 & 64 & $88,88 \%$ & S1 (Sangat sesuai) \\
Stasiun 2 & 59 & $81,94 \%$ & S1 (Sangat sesuai) \\
Stasiun 3 & 61 & $84,72 \%$ & S1 (Sangat sesuai) \\
\hline
\end{tabular}

\section{Analisis SWOT}

Faktor kekuatan, kelemahan, peluang, dan ancaman perlu dilakukan identifikasi untuk dapat mengetahui strategi pengelolaan dan pengembangan demi keberlangsungan kegiatan ekowisata. Penyusunan analisis SWOT dilakukan dengan mengidentifikasi variabel - variabel yang termasuk 
dalam faktor intenal dan eksternal. Perhitungan skor dari masing - masing variabel kemudian disusun sebagai matriks SWOT.

Tabel 6. Alternatif Strategi Pengelolaan

\begin{tabular}{|c|c|c|c|}
\hline Alternatif Strategi & Keterkaitan & Jumlah Skor & Peringkat \\
\hline \multicolumn{4}{|l|}{ Strategi S-O } \\
\hline 1. Membuat arena olahraga pantai & $\mathrm{S} 1, \mathrm{~S} 2, \mathrm{O} 2, \mathrm{O} 4$ & 1,975 & 3 \\
\hline 2. Membuat atraksi eduwisata tambak garam & $\begin{array}{l}\mathrm{S} 1, \mathrm{~S} 4, \mathrm{O} 1, \mathrm{O} 2 \\
\mathrm{O} 4\end{array}$ & 2,526 & 2 \\
\hline \multicolumn{4}{|l|}{ Strategi W-O } \\
\hline 1. Menambah petugas kebersihan & W2, 01 & 0,96 & 6 \\
\hline $\begin{array}{l}\text { 2. Memanfaatkan kondisi alam yang ada untuk } \\
\text { menambah daya tarik wisata }\end{array}$ & $\begin{array}{l}\text { W1, W4, O1 } \\
\quad \text { O2, O3 }\end{array}$ & 2,607 & 1 \\
\hline \multicolumn{4}{|l|}{ Strategi S-T } \\
\hline $\begin{array}{l}\text { 1. Membuat akses jalan lain menuju lokasi } \\
\text { wisata }\end{array}$ & $\mathrm{S} 1, \mathrm{~T} 1, \mathrm{~T} 2$ & 1,547 & 4 \\
\hline \multicolumn{4}{|l|}{ Strategi W-T } \\
\hline $\begin{array}{l}\text { 1. Pengembangan berbagai fasilitas dan daya } \\
\text { tarik objek wisata }\end{array}$ & W1, T2 & 1,047 & 5 \\
\hline
\end{tabular}

Secara fisik objek penelitian memiliki kecenderungan berpasir putih dengan butir pasir yang cukup halus. Hal ini menjadi nilai lebih untuk kegiatan wisata pantai, sesuai dengan pendapat Yulianda (2007) yang menyatakan bahwa pantai dengan pasir putih memiliki bobot dan skor tertinggi. Kondisi parameter fisik di Pantai Seribu Ranting cukup baik, walaupun terdapat beberapa parameter yang nilainya tidak sesuai dengan baku mutu yaitu kecerahan perairan. Kecerahan perairan Pantai Seribu Ranting hanya berkisar antara 15-17\% sedangkan menurut Yulianda (2007) kecerahan perairan yang sangat sesuai berkisar 75\%-100\%. Hal ini dikarenakan kondisi perairan Pantai Seribu Ranting yang cukup keruh. Kekeruhan perairan Pantai Seribu Ranting disebabkan oleh material dasar perairan yang berupa lanau berpasir sehingga apabila terdapat gelombang akan menyebabkan substrat dasar mudah teraduk. Kedalaman perairan yang cukup dangkal juga mempengaruhi kecerahan perairan. Perairan yang dangkal menyebabkan substrat lebih mudah teraduk oleh gelombang yang datang sehingga perairan menjadi cukup keruh. Kekeruhan air ini menyebabkan pengunjung hanya dapat menikmati kegiatan wisata air dengan bermain air di garis pantai atau menyewa ban untuk berenang di tepi pantai.

Rata - rata kecepatan arus di perairan Jepara yaitu 0,17 m/s. Menurut Tendiseru (2015) kecepatan arus tersebut tergolong lambat $(0,010,25 \mathrm{~m} / \mathrm{s})$. Kecepatan arus yang lambat ini cukup aman bagi kegiatan wisata pantai. Maksimum tinggi gelombang rata - rata tahunan di wilayah perairan Kedung yaitu 1,147 meter. Angka tersebut tergolong cukup sesuai untuk kegiatan wisata, dimana menurut Yulianda (2007) bahwa ketinggian gelombang 0,5 - 1 meter tergolong dalam skor 3 (sesuai). Ketersediaan air tawar yang baik untuk wisata menurut Handayawati (2010) adalah kurang dari 0,5 km. Pantai Seribu Ranting telah sesuai dengan ketersediaan sumber air tawar memiliki jarak kurang lebih 200 meter dari stasiun terjauh. Tidak adanya biota berbahaya di Pantai Seribu Ranting dapat dijadikan sebagai pertimbangan hal yang berdampak baik bagi kelayakan pantai ini sebagai kawasan wisata.

Parameter bau dan sampah mempengaruhi estetika objek wisata dan kenyamanan pengunjung. Pantai Seribu Ranting memiliki beberapa titik lokasi yang terdapat sampah yang menumpuk dan berserakan seperti pada stasiun 1. Stasiun 1 merupakan tempat terdekat bagi pengunjung untuk menikmati pasir pantai dan pemandangan laut. Pengunjung paling banyak 
mengunjungi lokasi ini. Kurangnya kesadaran pengunjung menyebabkan banyaknya sampah bekas makanan dan minuman yang berserakan. Faktor lain yang menyebabkan stasiun 1 terlihat kotor adalah sampah - sampah yang terbawa gelombang dari laut sehingga terdampar di pantai. Hal ini mengakibatkan pengelola harus terus melakukan pembersihan rutin secara berkala agar sampah - sampah bawaan dari laut tidak mengganggu pemandangan pantai wisata.

Salah satu daya tarik utama dari kegiatan wisata rekreasi pantai bagi wisatawan adalah menikmati keindahan alam. Pantai Seribu Ranting memiliki gisik pantai yang cukup lebar dan kemiringan yang landai dengan pasir putih yang menjadikan suatu kelebihan dibandingkan dengan pantai berbatu. Menurut Armos (2013), kemiringan pantai yang kurang dari $10^{\circ}$ tergolong dalam pantai yang datar sehingga banyak aktivitas yang dapat dilakukan dikawasan pantai berpasir seperti bermain pasir, voli pantai, perkemahan, dan lain sebagainya. Pantai Seribu Ranting juga memiliki panorama sunset yang elok, sehingga pengunjung dapat menikmati senja dengan indah.

Penyusunan rencana pengelolaan ekowisata pantai di Pantai Seribu Ranting dilakukan dengan melakukan skoring dan analisis SWOT. Analisis SWOT yang dilakukan di Pantai Seribu Ranting menghasilkan tiga prioritas utama, yaitu: memanfaatkan kondisi alam yang ada untuk menambah daya tarik wisata, membuat atraksi eduwisata tambak garam, dan membuat arena olahraga pantai.

Angin yang berhembus cukup kencang di lokasi wisata juga dapat dimanfaatkan sebagai daya tarik wisata. Lebar dan panjang pantai yang cukup luas dan landai juga mendukung untuk diadakan tambahan daya tarik wisata seperti festival layang-layang. Pengelola dapat mengadakan festival ini secara berkala untuk menarik daya kunjung wisatawan. Pengunjung dapat melihat berbagai jenis, bentuk, dan ukuran layang-layang yang mengikuti festival.

Pembuatan arena olahraga pantai juga dapat dilakukan untuk menambah minat kunjungan wisatawan. Pengelola dapat membuat lapangan voli pantai yang berstandar turnamen. Pantai Seribu Ranting memiliki keunggulan potensi alam yaitu adanya tambak garam yang berbatasan langsung dengan area pantai wisata. Atraksi eduwisata tambak garam dapat menjadi daya tarik tersendiri bagi wisatawan. Menurut Nurisjah (2006), prinsip dasar eduwisata adalah memberikan pengetahuan kepada wisatawan yang berkunjung ke suatu objek wisata. Pantai Seribu Ranting dapat menawarkan atraksi eduwisata dengan cara pengelola bekerja sama dengan masyarakat pemilik tambak garam untuk membuka lahannya sebagai tempat eduwisata.

\section{KESIMPULAN}

Nilai indeks kesesuaian wisata di Pantai Seribu Ranting Jepara untuk kategori wisata pantai yang dilakukan dengan mengkaji dan menganalisis parameter fisik di stasiun 1, stasiun 2, dan stasiun 3 menunjukkan angka diatas $80 \%$. Nilai IKW yang diperoleh pada masing - masing stasiun yaitu sebesar $88,88 \%$ pada stasiun $1,81,94 \%$ pada staisun 2 , dan $84,72 \%$ pada staisun 3 . Nilai IKW yang diperoleh tergolong dalam kelas kesesuaian $\mathrm{S} 1$ yang berarti sangat sesuai untuk kegiatan wisata pantai. Analisis SWOT di Pantai Seribu Ranting menghasilkan 3 (tiga) prioritas utama, yaitu: memanfaatkan kondisi alam yang ada untuk menambah daya tarik wisata, membuat atraksi eduwisata tambak garam, dan membuat arena olahraga pantai.

\section{DAFTAR PUSTAKA}

Armos, N.H. 2013. Studi Kesesuaian Lahan Pantai Wisata Boe Desa Mappakalompo Kecamatan Galesong Ditinjau Berdasarkan Biogeofisik. Universitas Hasanuddin. Makassar.

Badan Meteorologi dan Geofisika. 2018. Data Suhu, Arus, dan Gelombang, Stasiun Meteorologi Semarang. Semarang.

Dewi, P.C. 2017. Studi Kelayakan Pantai Bagus Sebagai Daerah tujuan Wisata di Kabupaten Lampung Selatan. Universitas Islam Negeri Syarif Hidayatullah. Jakarta.

Fendeli, C. 2000. Pengertian dan Konsep Dasar Pariwisata. Universitas Gadjah Mada. Yogyakarta.

Handayawati, H. S., Budiono, dan Soemarmo. 2010. Potensi Wisata Alam Pantai Bahari. PM PSLP PPSUB. Jawa Timur. 
Haris, A. 2003. Analisis Kesesuaian Lahan dan Kebijakan Pemanfaatan Ruang Wilayah Pesisir Teluk Kayeli Kabupaten Buru. Institut Pertanian Bogor. Bogor.

Nurisjah, S. 2006. Pengembangan Interpretasi Wisata Pesisir Guna Mendukung Program Pendidikan Sumber Daya Pesisir dan Kelautan: Kumpulan Riset Kelautan. Bogor.

Pemerintah Desa Panggung Kecamatan Kedung Kabupaten Jepara. 2018. Laporan Keterangan Pelaksanaan Pemerintahan Desa. Jepara.

Prihantanto, D.N.A., Pratikto, I. \& Irwani. 2014. Studi Kesesuaian Wisata di Pantai Sendang Sikucing Kabupaten Kendal Sebagai Objek Wisata Rekreasi Pantai. Universitas Diponegoro. Semarang.

Puspita, P. P. S. 2015. Konsep Pengembangan Ekowisata Mangrove Berbasis Masyarakat di Desa Pasar Banggi, Kabupaten Rembang. Institut Pertanian Bogor. Bogor.

Rangkuti, F. 2005. Analisis SWOT: Teknik Membelah Kasus Bisnis. PT. Gramedia. Jakarta. 200 hlm.

Tendiseru, N. 2015. Studi Kondisi Oseanografi untuk Kesesuaian Lahan Wisata Pantai di Pulau Camba Cambang Kabupaten Pangkep. Universitas Hasanuddin. Makassar.

Wunani, D. 2014. Kesesuaian Lahan dan Daya Dukung Kawasan Wisata Pantai Batutonuo Kecamatan Kabila Bone Kabupaten Bone Belango. Universitas Negeri Gorontalo. Gorontalo.

Yulianda, F. 2007. Ekowisata Bahari sebagai Alternatif Pemanfaatan Sumberdaya Pesisir Berbasis Konservasi. FPIK IPB. Bogor. Disampaikan pada Seminar Sains 21 Februari 2007 pada Departemen Manajemen Sumberdaya Perairan. Fakultas Perikanan dan IImu Kelautan. IPB. Bogor. Hal 125. 